\title{
Biological Significance of Mefenoxam Resistance in Phytophthora erythroseptica and Its Implications for the Management of Pink Rot of Potato
}

\author{
Raymond J. Taylor, Julie S. Pasche, and Neil C. Gudmestad, Department of Plant Pathology, North Dakota State \\ University, Fargo 58105
}

\begin{abstract}
Taylor, R. J., Pasche, J. S., and Gudmestad, N. C. 2006. Biological significance of mefenoxam resistance in Phytophthora erythroseptica and its implications for the management of pink rot of potato. Plant Dis. 90:927-934.

Tubers from plants treated with in-furrow and foliar applications of mefenoxam were inoculated with eight isolates of Phytophthora erythroseptica having varying levels of sensitivity to the fungicide. Two isolates with effective concentration causing $50 \%$ reduction of mycelial growth $\left(\mathrm{EC}_{50}\right.$ ) values of 0.02 and $0.04 \mu \mathrm{g} \mathrm{ml}^{-1}$ were categorized as being mefenoxam sensitive. Isolates with $\mathrm{EC}_{50}$ values $>1.0 \mu \mathrm{g} \mathrm{ml}^{-1}$ were designated as insensitive to mefenoxam and were grouped two each into low intermediate $\left(\mathrm{EC}_{50}=1.1\right.$ and $\left.5.3 \mu \mathrm{g} \mathrm{ml}^{-1}\right)$, high intermediate $\left(\mathrm{EC}_{50}=26\right.$ and $\left.74 \mu \mathrm{g} \mathrm{ml}^{-1}\right)$, and resistant $\left(\mathrm{EC}_{50} \geq 100 \mu \mathrm{g} \mathrm{ml}^{-1}\right)$. The biological significance of these isolates was examined by quantifying disease control. P. erythroseptica isolates classified in the resistant group infected a significantly greater proportion of untreated tubers than isolates in any other group. Mefenoxam reduced infection frequency of sensitive isolates by as much as $37 \%$. Mefenoxam did not provide disease control of any isolate possessing insensitivity to the fungicide, with the greatest decrease in control observed with the low intermediate group. Aggressiveness indices, representing tuber infection frequency and depth of penetration, were calculated for untreated and mefenoxam-treated tubers. According to these indices, both isolates classified in the resistant group and high intermediate isolate 252-4 were more aggressive than sensitive isolates in the absence of mefenoxam pressure, and significantly so in the presence of mefenoxam. These results suggest that pink rot may become more severe in fields known to contain P. erythroseptica populations with mefenoxam $\mathrm{EC}_{50}$ values $>1.0 \mu \mathrm{g} \mathrm{ml}^{-1}$ if the fungicide is applied. These factors should be considered when developing strategies to manage pink rot and mefenoxam-resistant populations of $P$. erythroseptica.
\end{abstract}

Additional keywords: metalaxyl, Ridomil Gold EC, Solanum tuberosum, Ultra Flourish EC, water rot

Pink rot, a soilborne disease of potato (Solanum tuberosum L), can be found in potato-growing regions throughout the world. The disease, caused by Phytophthora erythroseptica Pethybr., often is exacerbated under conditions of high moisture, such as in low-lying areas, areas with poorly drained soils, or during periods of extended rainfall and warm temperatures late in the growing season (22). Pink rot may be distributed widely within potato fields and storages and can result in severe yield losses both before and after harvest when conditions are favorable $(4,33,38)$. This disease primarily affects potato tubers, causing a watery breakdown of infected tissue. The tissue may remain relatively firm and rubbery but becomes a distinct pink color after exposure to air for 20 to $30 \mathrm{~min}$. Under conditions favoring

Corresponding author: N. C. Gudmestad

E-mail: Neil.Gudmestad@ndsu.edu

Accepted for publication 1 March 2006.

DOI: 10.1094/PD-90-0927

(C) 2006 The American Phytopathological Society severe pink rot, stem and root infections with symptoms similar to blackleg also may occur (22). In extreme cases, entire areas of infected fields may not be harvested.

In addition to potato, $P$. erythroseptica also has the ability to infect numerous other solanaceous and nonsolanaceous species (22). It is endemic to most soils and is able to survive as oospores in infected plant tissue or debris for many years. The pathogen can be introduced into uninfested soils by infected seed tubers (10). Tuber infections, initiated by germinating oospores, generally occur through the stolons but the pathogen also may gain entry through the eyes or lenticels via zoospores $(22,23)$. P. erythroseptica also can infect tubers through cuts, cracks, or other wounds made during harvest operations (36).

Most cultivars commonly grown in North America are susceptible to pink rot (35) and, aside from a report describing a technique for rapid evaluation of potato germ plasm for resistance to pink rot at the seedling stage (28) and a nontraditional approach involving the development of transgenic potato lines expressing a cati- onic peptide conveying resistance to the disease (25), research efforts to improve cultivar resistance to $P$. erythroseptica currently are lacking. Traditional breeding programs have yet to direct efforts toward developing lines showing significant resistance to the disease. As a result, management strategies generally are aimed at conditions that disfavor infection and disease development. These strategies are usually cultural in nature and involve such practices as crop rotation, planting the potato crop in well-drained soils, avoiding excessive irrigation at the end of the growing season, allowing sufficient time between vine killing and harvest for proper periderm development, modifying tuber handling procedures to reduce wounding, and harvesting when tuber pulp temperatures are below $21^{\circ} \mathrm{C}(22,33,38)$.

Although growers can manage pink rot successfully by implementing such techniques, field applications of mefenoxam, the R-enantiomer of the parent isomer metalaxyl (Ridomil Gold EC and Ultra Flourish EC), continue to provide the most effective means of controlling the disease $(29,31,41,46)$. Originally introduced as metalaxyl in 1977, this phenylamide fungicide has been used on a variety of crops to control diseases caused by the Peronosporales. However, within 2 years of its introduction, resistance to metalaxyl was found in populations of Pseudoperonospora cubensis (34) and Phytophthora infestans $(11,12)$. Resistance of $P$. erythroseptica to metalaxyl first was detected in isolates collected from infected potato tubers in Aroostook County, ME in 1993 (21) and since has been documented in other potato-growing areas in North America $(14,42)$. In one of these studies, sensitivity of $P$. erythroseptica isolates to mefenoxam ranged from $<0.05$ to $>100 \mu \mathrm{g}$ $\mathrm{ml}^{-1}$ (43), with a significant proportion having an "intermediate" response to the fungicide. Based upon isolate in vitro growth responses, recent studies defined three levels of mefenoxam sensitivity in those populations $(29,31,42,43)$. Isolates with effective concentration causing $50 \%$ reduction of mycelial growth $\left(\mathrm{EC}_{50}\right)$ values below $1.0 \mu \mathrm{g} \mathrm{ml}^{-1}$ have been characterized as being sensitive to the fungicide whereas others were classified as being resistant $\left(\mathrm{EC}_{50}>100 \mu \mathrm{g} \mathrm{ml}^{-1}\right)$, readily growing on media amended with mefenoxam. The growth responses of other isolates fall somewhere between these values $\left(\mathrm{EC}_{50}=\right.$ 
1.0 to $99.9 \mu \mathrm{g} \mathrm{ml}{ }^{-1}$ ). Such isolates are moderately sensitive or considered to have an intermediate level of resistance to mefenoxam. These designations are somewhat arbitrary and possibly may not reflect the true nature of response to mefenoxam within a biological system under field conditions. The biological significance of the in vivo reaction of $P$. erythroseptica isolates to mefenoxam, especially those showing an intermediate level of insensitivity, has been largely overlooked.

Although mefenoxam still provides reliable control of pink rot in most areas of the United States, the existence of mefenoxam resistance in the $P$. erythroseptica population has implications for the management of the disease (42). Given the range of mefenoxam sensitivity that can exist in resident field populations of the pathogen, a prerequisite for successful implementation of a program to manage pink rot and fungicide resistance would be to determine the relationship between the level of resistance estimated via in vitro testing and the efficacy of the mefenoxam applications under field conditions. The current study was undertaken to examine this relationship and how it affects development of pink rot in potato and, ultimately, disease management. Experiments were conducted to determine the efficacy of field applications of mefenoxam against isolates of $P$. erythroseptica exhibiting a broad range of responses to the fungicide in order to determine the biological significance of the mefenoxam sensitivities of such isolates and to derive an estimation of their competitive ability.

\section{MATERIALS AND METHODS}

Source of isolates. During a survey of the North American population of $P$. erythroseptica (42), 805 isolates were obtained from 2,770 tubers with "water rot" symptoms collected from commercial potato fields and storages in 16 states and two Canadian provinces. Isolates were collected by transferring small pieces of in- fected tissue, approximately $25 \mathrm{~mm}^{3}$ in size, to culture dishes containing water agar amended with ampicillin $\left(100 \mu \mathrm{g} \mathrm{ml}^{-1}\right)$ and incubated in the dark at 17 to $20^{\circ} \mathrm{C}$ for 3 to 5 days. Colonies with mycelia resembling that of $P$. erythroseptica were selected and purified by hyphal tipping. Isolates recovered were identified based upon morphological characteristics described by Stamps et al. (39). Isolates were maintained on clarified V8 juice agar medium (10\% V8 juice filtered through four layers of cheesecloth, $0.1 \% \mathrm{CaCO}_{3}$, and $2 \%$ agar) in the dark at $20 \pm 1^{\circ} \mathrm{C}$ and isolate pathogenicity was confirmed via tuber inoculation (cv. Russet Burbank).

Mefenoxam sensitivity. Mefenoxam (Ridomil Gold 4EC) sensitivity was determined for all 805 isolates using an in vitro screening method described previously $(1,41-43)$. Tests were conducted on modified V8 juice agar (5\% V8 juice filtered through four layers of cheesecloth and $2 \%$ agar) amended with fungicide in a 10 -fold dilution series ranging from 0.01 to $100 \mu \mathrm{g} \mathrm{ml} \mathrm{m}^{-1}$ and control plates unamended with mefenoxam. A cork borer was used to excise 5-mm-diameter disks containing mycelium and agar from the margin of actively growing colonies of 4to 6-day-old cultures. Each disk was positioned in the center of a 9-cm culture dish with the mycelium in contact with the test medium. The dishes contained $17 \mathrm{ml}$ of amended medium and testing was done in duplicate at each concentration.

Isolate growth was determined by measuring colony diameters in two perpendicular directions after 6 days of incubation in the dark at $20 \pm 1^{\circ} \mathrm{C}$. Measurements were averaged, the diameter of the mycelial plug was subtracted, and relative growth reduction for each rate of fungicide was calculated as follows: (100 - [growth with fungicide/growth in control plate] $\times 100)(1$, 42). The $\mathrm{EC}_{50}$ relative to the control was estimated by plotting the percentage inhibition against the log-scale of fungicide concentration. Two independent trials were

Table 1. Effective concentration causing $50 \%$ reduction of mycelial growth $\left(\mathrm{EC}_{50}\right)$ values and aggressiveness indices of eight Phytophthora erythroseptica isolates from four mefenoxam sensitivity groups used in the challenge inoculation study

\begin{tabular}{|c|c|c|c|c|c|c|}
\hline \multirow[b]{2}{*}{ Isolate } & \multirow[b]{2}{*}{ State of origin } & \multirow[b]{2}{*}{$\mathrm{EC}_{50}\left(\mu \mathrm{g} \mathrm{ml}^{-1}\right)$} & \multirow[b]{2}{*}{ Group $^{y}$} & \multicolumn{3}{|c|}{ Aggressiveness index $^{x}$} \\
\hline & & & & Untreated & In-furrow & Foliar \\
\hline $266-2$ & Washington & 0.02 & S & $1,380.4 \mathrm{bcd}$ & $847.3 \mathrm{c}$ & $1,138.7 \mathrm{e}$ \\
\hline $364-5$ & Minnesota & 0.04 & $\mathrm{~S}$ & $1,361.9 \mathrm{bcd}$ & $1,101.2 \mathrm{c}$ & $1,344.7 \mathrm{cde}$ \\
\hline $188-4$ & Idaho & 1.1 & LI & $1,130.6 \mathrm{~cd}$ & $1,652.0 \mathrm{ab}$ & $1,703.1 \mathrm{c}$ \\
\hline $285-3$ & Idaho & 5.3 & LI & $986.6 \mathrm{~d}$ & $1,616.3 \mathrm{~b}$ & $1,635.5 \mathrm{~cd}$ \\
\hline $252-4$ & Minnesota & 26 & HI & $1,575.0 \mathrm{bc}$ & $1,972.5 \mathrm{ab}$ & $2,251.0 \mathrm{ab}$ \\
\hline $172-3$ & Idaho & 74 & HI & $1,102.4 \mathrm{~d}$ & $1,038.9 \mathrm{c}$ & $1,203.1 \mathrm{de}$ \\
\hline $217-1$ & Idaho & $170^{z}$ & $\mathrm{R}$ & $1,622.6 \mathrm{~b}$ & $1,841.5 \mathrm{ab}$ & $1,830.5 \mathrm{bc}$ \\
\hline PE-89 & Maine & 239 & $\mathrm{R}$ & $2,081.0 \mathrm{a}$ & $2,160.8 \mathrm{a}$ & $2,436.5 \mathrm{a}$ \\
\hline
\end{tabular}

${ }^{\mathrm{x}}$ Aggressiveness index $=$ tuber rot incidence $\times$ tuber rot penetration. Mean separation based on Fisher's protected least significant difference test $(P=0.05)$. Means within columns followed by the same letter are not significantly different.

${ }^{y}$ Mefenoxam sensitivity: $\mathrm{S}=$ mefenoxam sensitive, $\mathrm{LI}=$ low intermediate, $\mathrm{HI}=$ high intermediate, and $\mathrm{R}=$ resistant.

${ }^{\mathrm{z}}$ Actual $\mathrm{EC}_{50}$ value based on single year determination. conducted to determine the $\mathrm{EC}_{50}$ values for each sensitivity test.

Isolates have been maintained in our culture collection on clarified V8 juice agar medium and carrot tissue in water at $4^{\circ} \mathrm{C}$ for approximately 5 years. Isolates were inoculated to potato tubers (cv. Russet Burbank) and reisolated on water agar medium to maintain pathogenicity and aggressiveness each year. Infection rates of the test isolates were typical of those collected more recently. Mefenoxam sensitivity also was assessed each year and the eight isolates used in this study were selected from the group of isolates collected in the North American survey to encompass a broad range of mefenoxam sensitivities and represent a sampling of the $P$. erythroseptica population over a diverse geographic area (Table 1). In vitro radial growth of the eight selected isolates also was compared across the range of mefenoxam concentrations used in the sensitivity testing with an additional level of fungicide $\left(0.001 \mu \mathrm{g} \mathrm{ml}^{-1}\right)$. Dose response curves were generated for individual $P$. erythroseptica isolates by plotting colony growth against log of the mefenoxam concentration.

Isolates were chosen on the basis of in vitro $\mathrm{EC}_{50}$ values (Table 1) and radial growth curves (Fig 1A) to represent four sensitivity groups (Fig. 1B). Isolates 266-2 and 364-5 represent the group sensitive to mefenoxam $\left(\mathrm{EC}_{50}<1.0 \mu \mathrm{g} \mathrm{ml}^{-1}\right)$ and isolates 217-1 and PE-89 are considered to be resistant to the fungicide $\left(\mathrm{EC}_{50} \geq 100 \mu \mathrm{g}\right.$ $\mathrm{ml}^{-1}$ ). The four isolates with intermediate sensitivity $\left(\mathrm{EC}_{50}=1.0\right.$ to $\left.99.9 \mu \mathrm{g} \mathrm{ml}^{-1}\right)$, 188-4, 285-3, 252-4, and 172-3, were further subclassified as low intermediate $\left(\mathrm{EC}_{50}=1.1\right.$ and $\left.5.3 \mu \mathrm{g} \mathrm{ml}^{-1}\right)$ and high intermediate $\left(\mathrm{EC}_{50}=26\right.$ and $\left.74 \mu \mathrm{g} \mathrm{ml}{ }^{-1}\right)$ sensitivity types (Table 1 ). Levene's test confirmed the validity of the isolate classifications, because variance homogeneity existed in 22 of the 28 variables among the four designated sensitivity groups across all seven concentrations assessed in the in vitro radial growth rate experiment (24).

Field plots and mefenoxam application. Fungicide application trials were conducted under center pivot irrigation at different locations over two consecutive growing seasons. In 2003, certified seed of Russet Norkotah, a cultivar highly susceptible to pink rot (35), was planted in research plots near Tappen, ND on 8 May. The 2004 mefenoxam trial was planted in a designated section of a commercial potato production field near Park Rapids, MN on 20 April using certified seed of the moderately susceptible cv. Russet Burbank (35). Three production blocks were established each year to provide different levels of pink rot control in treated versus untreated tubers. In 2003, each block consisted of a four-row by 75-m layout; in 2004, eight rows by $50 \mathrm{~m}$ were used. Fungicide was applied at the recommended 
label rate each year. One block received mefenoxam (Ridomil Gold 4EC) as an infurrow application of $200 \mathrm{~g}$ a.i. ha ${ }^{-1}$ at planting followed by an additional sidedress application of $100 \mathrm{~g}$ a.i. $\mathrm{ha}^{-1} 21$ days later. This split application of mefenoxam at these rates previously has been demonstrated to provide the highest level of pink rot control (41). Another block was treated with two foliar applications of $100 \mathrm{~g}$ a.i. $\mathrm{ha}^{-1}$ when tubers were 7 to $8 \mathrm{~mm}$ in diameter and 14 days later. The remaining block was left untreated. The production blocks were separated by $2 \mathrm{~m}$ planted to winter wheat in 2003 and potato (cv. Russet Burbank) in 2004. Both mefenoxam application trials were managed using agronomic practices typical of those recommended for irrigated potato production in the respective regions.

Postharvest inoculation. Plants were killed by mechanical flailing 2 to 3 weeks prior to maturity to insure the availability of a sufficient quantity of tubers of the desired size and adequate skin set. After harvest, tubers were stored for 2 weeks at $15^{\circ} \mathrm{C}$ and $90 \%$ relative humidity to facilitate wound healing. Studies have demonstrated residual bioactivity of the fungicide after 4 to 6 months in storage $(2,8,32)$. However, because levels of mefenoxam in tubers will decline over time, test tubers used in this study were stored at $10^{\circ} \mathrm{C}$ for no longer than 3 months prior to testing. For challenge inoculations with the $P$. erythroseptica isolates, disease-free tubers (140 to $190 \mathrm{~g}$ ) with apical eyes free of soil and having an intact periderm were acclimated at room temperature $\left(20\right.$ to $\left.25^{\circ} \mathrm{C}\right)$ for 1 to 2 days. Surface sterilization does not affect frequency of $P$. erythroseptica infection (35); therefore, tubers were not washed or surface disinfested prior to inoculation.

Inoculum preparation and application methods were similar to those described previously $(35,41)$. Zoospores were obtained using a procedure based upon a technique described by Vujicic and Colhoun (45), except that clarified V8 juice agar ( $100 \mathrm{ml}$ of clarified V8 juice, $15 \mathrm{~g}$ of agar, and $900 \mathrm{ml}$ of deionized $\mathrm{H}_{2} \mathrm{O}$ ) and clarified V8 juice broth ( $100 \mathrm{ml}$ of clarified V8 juice and $900 \mathrm{ml}$ of deionized $\mathrm{H}_{2} \mathrm{O}$ ) were substituted for pea extract medium. Test isolates were grown on culture plates containing clarified V8 juice agar at ambient temperature $\left(20\right.$ to $\left.25^{\circ} \mathrm{C}\right)$. After 3 days, 5-mm-diameter disks containing mycelium and agar were removed from the margin of the colonies and placed in culture plates containing autoclaved clarified V8 broth. These plates were incubated in the dark at ambient temperature $\left(20\right.$ to $\left.25^{\circ} \mathrm{C}\right)$ for 3 days. After removing the clarified V8 juice broth from the plates, the mycelial mats were rinsed twice with sterile deionized $\mathrm{H}_{2} \mathrm{O}$ followed by the addition of $10 \mathrm{ml}$ of autoclaved, filtered soil extract from a potato field (10\% soil) to each plate. Spo- rangial formation occurred after 36 to $48 \mathrm{~h}$ of incubation under constant illumination (eight Sylvania F20T12/CW lamps) in an environmentally controlled incubator $(20 \pm$ $\left.1^{\circ} \mathrm{C}\right)$. Zoospore release was stimulated by chilling cultures at $10 \pm 1^{\circ} \mathrm{C}$ for $1 \mathrm{~h}$ followed by a warming period at 20 to $25^{\circ} \mathrm{C}$. Inoculum concentration was determined with a hemacytometer and adjusted to $2 \times$ $10^{4}$ zoospores $\mathrm{ml}^{-1}$. Zoospore suspensions were held in the dark at 8 to $10^{\circ} \mathrm{C}$ until inoculations were carried out, generally within 10 to $60 \mathrm{~min}$. Test tubers, selected at random from the three field treatments, were placed in plastic moist chamber boxes ( 33 by 24 by $12 \mathrm{~cm}$ ) lined at the bottom with no. 3 plastic mesh and inoculated with $10 \mu \mathrm{l}$ of the zoospore suspension (approximately 200 zoospores) on each of three apical eyes. Inoculated tubers were covered with four layers of paper towels moistened to saturation with deionized water. The chamber boxes were sealed to establish high humidity to promote infection. The chambers were incubated in the dark at ambient temperature at 20 to $22^{\circ} \mathrm{C}$ for 10 days.

Postharvest challenge inoculations were conducted on a total of 320 tubers per treatment (four replications $\times 40$ tubers $\times$ two inoculation trials) in 2003 and a total of 240 tubers per treatment (four replications $\times 20$ tubers $\times$ three trials) in 2004. In all trials, tubers were selected randomly from each treatment with approximately 2 week intervals between inoculation trials.

Disease assessment. Pink rot development was quantified using techniques similar to those described in earlier work $(35,41)$. Inoculated tubers were removed from the moist chambers and infection was determined by cutting each tuber in half through the axis from the sites of inoculation on the apical bud end to the basal stem
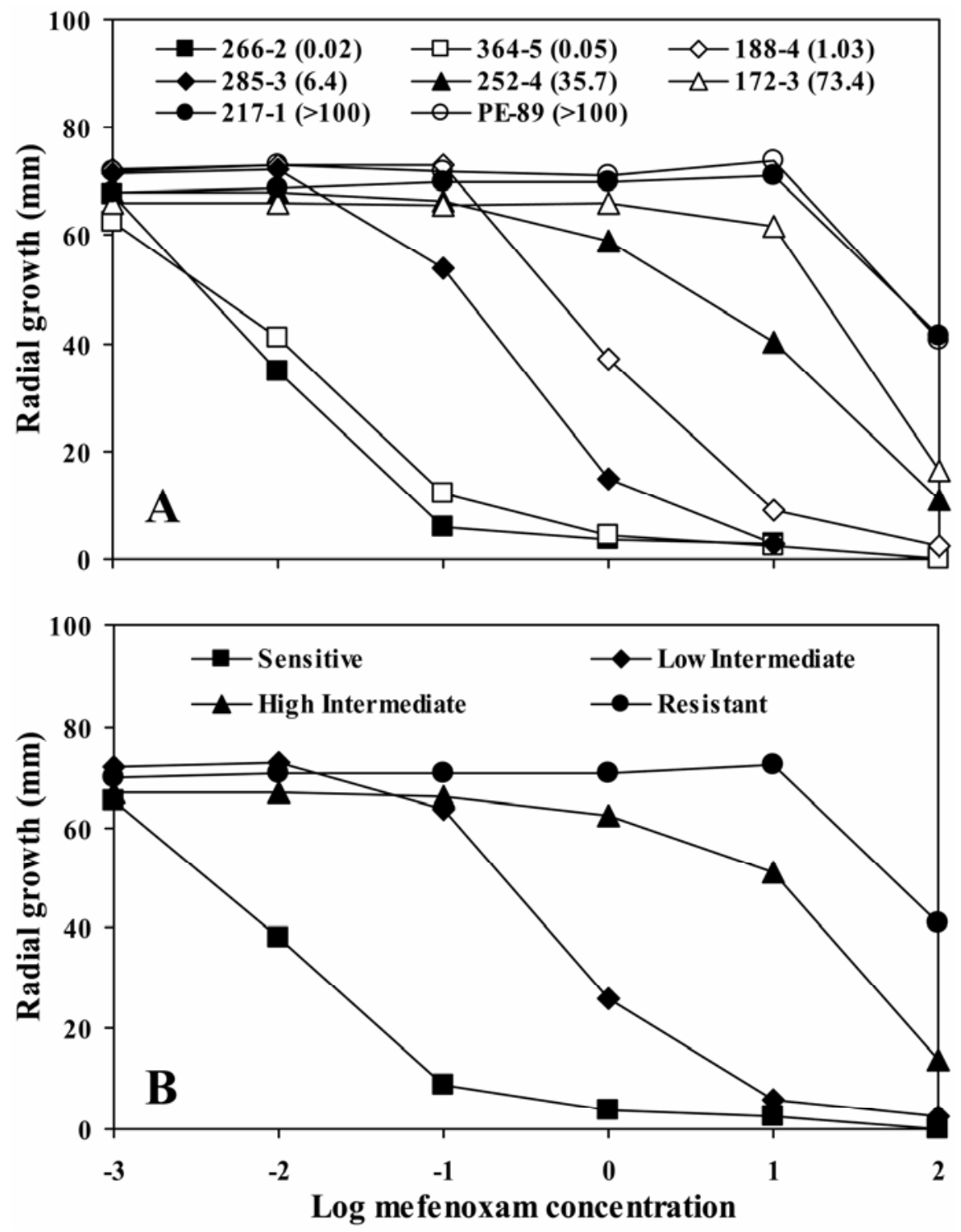

Fig. 1. Radial growth in millimeters for $\mathbf{A}$, eight Phytophthora erythroseptica isolates and $\mathbf{B}$, mefenoxam sensitivity groups after $139 \mathrm{~h}$ on medium amended with mefenoxam at $0.001,0.01,0.1,1.0$ 10.0 , and $100.0 \mu \mathrm{g} \mathrm{ml}^{-1}$. Calculated effective concentration causing $50 \%$ reduction of mycelial growth values are stated parenthetically after isolate designation in A. 
end. Split tubers were covered with moist paper towels and incubated at ambient temperatures of 20 to $24^{\circ} \mathrm{C}$ for approximately $30 \mathrm{~min}$ to enhance the development of the discoloration diagnostic of pink rot. Infected tubers were counted and disease incidence was calculated as number of diseased tubers/number of inoculated tubers $) \times 100$. To determine pink rot severity, the maximum width of rot $(\mathrm{W})$ and the depth (D) of rot from the inoculation point were measured and penetration $(\mathrm{P})$ of rot was calculated as $\mathrm{P}=(\mathrm{W} / 2+[\mathrm{D}-5]) / 2$. Disease incidence was transformed to percent disease control using the formula ([disease incidence of untreated control disease incidence of treatment $] /$ disease incidence of untreated control) $\times 100$.

Experimental design and statistical analysis. Tuber rot incidence among untreated tubers across the five inoculation trials was tested for variance homogeneity using Levene's method. This method also was used to test homogeneity within the four mefenoxam sensitivity groups for both tuber rot incidence and transformed disease control data. One-way analyses of variance (ANOVAs) were performed using the general linear model of SAS (PROC GLM; SAS Institute, Inc, Cary, NC) and mean percent tuber rot and disease control were differentiated using Fisher's protected least significant difference (LSD) test $(P=0.05)$. In vitro $\mathrm{EC}_{50}$ values $(\mu \mathrm{g}$ $\mathrm{ml}^{-1}$ ) among individual isolates with some level of resistance to mefenoxam were compared with the mean percentage of disease reduction of foliar and in-furrow fungicide treatments by means of exponential regression analyses. Incidence (I) and depth of penetration $(\mathrm{P})$ were used to develop an aggressiveness index (Ai) for each isolate where $\mathrm{Ai}=\mathrm{I} \times \mathrm{P}$. As a measure

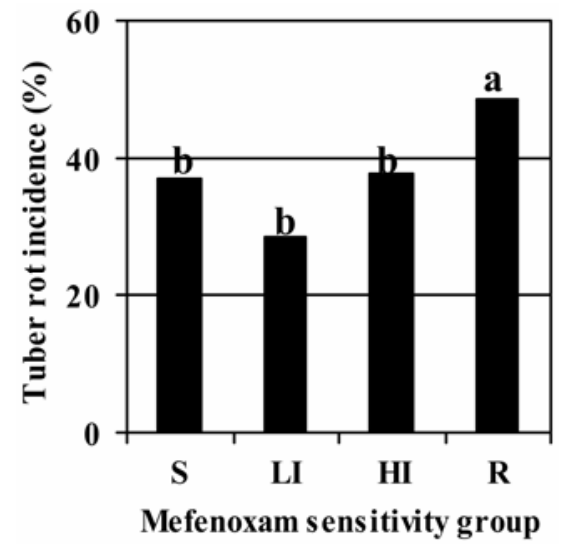

Fig. 2. Pink rot incidence (percent tuber infection) of four Phytophthora erythroseptica mefenoxam sensitivity groups in tubers from plants not treated with mefenoxam. Columns with the same letter are not statistically different based on Fisher's protected least significant difference test $(P=0.05)$. Letters on $\mathrm{X}$-axis represent mefenoxam sensitivity groups; $\mathrm{S}=$ sensitive, $\mathrm{LI}$ = low intermediate, $\mathrm{HI}=$ high intermediate, and $\mathrm{R}=$ resistant. of response to the fungicide, aggressiveness indices were ascertained both with and without mefenoxam pressure. Again, one-way ANOVAs were performed and mean aggressiveness indices compared $P$. erythroseptica isolates inoculated onto untreated, foliar, and in-furrow mefenoxam-treated tubers using Fisher's protected LSD test $(P=0.05)$.

\section{RESULTS}

Isolate pathogenicity. Percent tuber rot incidence data in tubers from plants not treated with mefenoxam in all five trials were determined to be homogeneous using Levene's method and subsequently were combined for further analysis. Individual isolate variances for pink rot disease incidence data also did not differ significantly using Levene's method; therefore, these data were combined into four mefenoxam sensitivity groups (sensitive, low intermediate, high intermediate, and resistant), as previously described for the in vitro data.

Percent tuber rot incidence in untreated tubers from field trials varied significantly among mefenoxam sensitivity groups $(P=$ 0.0012 ; Fig. 2), with mean infection rates
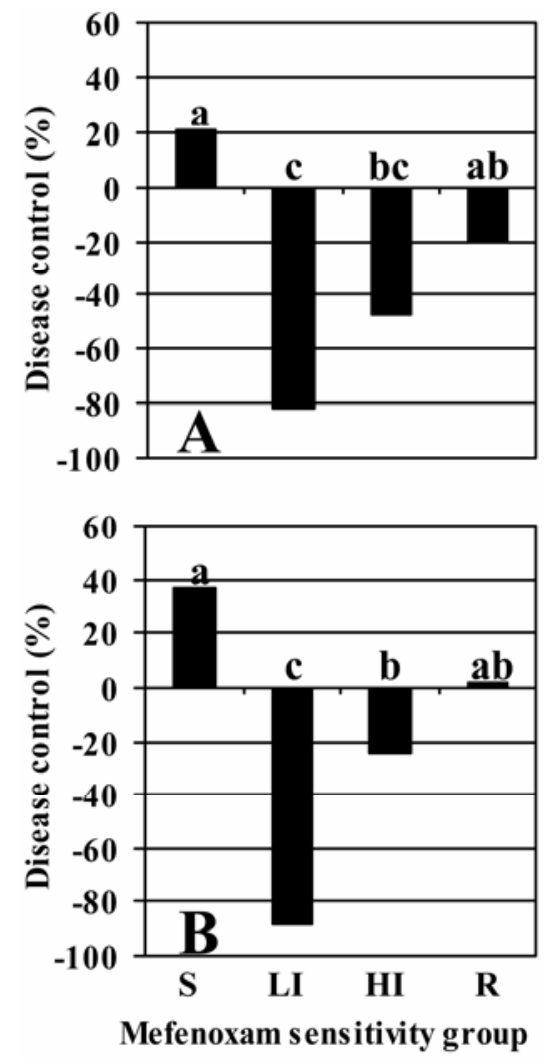

Fig. 3. Disease control (percent of untreated) of four Phytophthora erythroseptica isolate sensitivity groups in tubers from plants treated with $\mathbf{A}$, foliar or $\mathbf{B}$, in-furrow applications of mefenoxam. Percentage of disease control values with the same letter are not statistically different based on Fisher's protected least significant difference test $(P=0.05)$. Letters on $\mathrm{X}$-axis represent mefenoxam sensitivity groups; $\mathrm{S}=$ sensitive, LI = low intermediate, $\mathrm{HI}=$ high intermediate, and $\mathrm{R}=$ resistant. ranging from 28.5 to $46.8 \%$. The lowest rates of infection of untreated tubers were obtained with low intermediate isolates; however, the infection frequency of this group did not differ significantly from that of either the sensitive or high intermediate isolate groups. Conversely, resistant isolates were associated with the highest infection frequencies of untreated tubers, causing significantly more tuber rot than any other group. Once infection occurred, all isolates readily grew within the tuber tissue. Disease severity, expressed as depth of penetration of infected tissue, ranged from 33.5 to $36.0 \mathrm{~mm}$. However, the differences in penetration observed among the isolates were not significant $(P=$ 0.9494; data not shown).

Pink rot control in mefenoxamtreated tubers. Because a significant difference was observed in infection of untreated tubers among all isolates $(P=$ 0.0025; data not shown), the data were transformed into percent disease control based on infection of treated versus untreated tubers. As with the tuber rot incidence data, individual isolate variances for the transformed disease control data were homogeneous within the four mefenoxam sensitivity groups. Numerically, in-furrow mefenoxam application provided more control of pink rot than did foliar application for all isolate groups except low intermediate, including a nearly twofold increase in percent disease control of mefenoxam-sensitive isolates (Fig. 3A and B). In-furrow and foliar mefenoxam treatment reduced mean pink rot incidence in tubers inoculated with sensitive isolates by 37 and $21 \%$, respectively (Fig. $3 \mathrm{~A}$ and $\mathrm{B}$ ). Disease control of sensitive isolates was significantly higher $(P<0.0001)$ than the level of disease control observed with the two intermediate groups with both foliar and in-furrow applications (Fig. 3A and B). This apparent stimulation of the rate of infection (= negative disease control) was most dramatic in the case of the low intermediate isolate group $\left(\mathrm{EC}_{50}=1\right.$ to $5 \mu \mathrm{g}$ $\mathrm{ml}^{-1}$ ) within both application methods. Disease control of resistant isolates also was compromised, but not significantly so. The relationship between disease control and the $\mathrm{EC}_{50}$ of mefenoxam-resistant isolates was determined to be exponential ( $r=$ 0.91 ) using the mean of the in-furrow and foliar applications of mefenoxam $(P=$ 0.0115; Fig. 4).

Mefenoxam effects on disease development. The effect of mefenoxam treatment on disease incidence and severity, a measure of aggressiveness, differs among the mefenoxam sensitivity groups (Fig. 5). A shift toward the origin of the $\mathrm{X}-\mathrm{Y}$ axes, relative to the untreated control, occurred following inoculation of mefenoxamtreated tubers with sensitive $P$. erythroseptica isolates (Fig. 5A). The shift towards the $\mathrm{X}-\mathrm{Y}$ origin is most evident in tubers treated with in-furrow applications of me- 
fenoxam and represents an overall reduction in pink rot development through the use of this fungicide. In contrast, pink rot disease development was enhanced, represented by a shift away from the origins of the X-Y axes, in groups with reduced sensitivity following mefenoxam treatment (Fig. 5B-D), clearly indicating increased pink rot severity. The pattern was similar for all isolates possessing some level of mefenoxam insensitivity and the shift was most dramatic in the case of the low intermediate group (Fig. 5B). This measure of aggressiveness again illustrates that, overall, resistant isolates caused the highest disease severity (Fig 5D).

Isolate aggressiveness and mefenoxam sensitivity. The $P$. erythroseptica isolates used in these studies varied considerably in aggressiveness. Significant differences in aggressiveness indices were observed among isolates inoculated onto untreated $(P=0.0002)$, foliar mefenoxam treatments $(P<0.0001)$, and in-furrow mefenoxam treatments $(P<0.0001)$ (Table1). Resistant isolate PE- 89 had a significantly greater aggressiveness index than any of the other seven isolates on non-mefenoxam-treated tubers. Low intermediate isolate 285-3 had the lowest aggressiveness index, which differed significantly from high intermediate isolate $252-4$ and both resistant isolates but not from the sensitive isolates 266-2 and 364-5. Aggressiveness of both sensitive isolates fell within the range of the insensitive isolates but did not differ significantly from isolates 188-4, 285-3, 252-4, 172-3, and 217-1.

Overall, the aggressiveness index values of the test isolates paralleled disease incidence and disease control data described earlier (Figs. 2 and 3). Isolates of P. erythroseptica with insensitivity to mefenoxam generally were more aggressive in tubers treated with the fungicide compared with sensitive isolates. In many instances, me-

$$
\operatorname{EC}_{50}\left(\mu \mathrm{g} \mathrm{ml}^{-1}\right)
$$

$\begin{array}{llllll}0 & 50 & 100 & 150 & 200 & 250\end{array}$

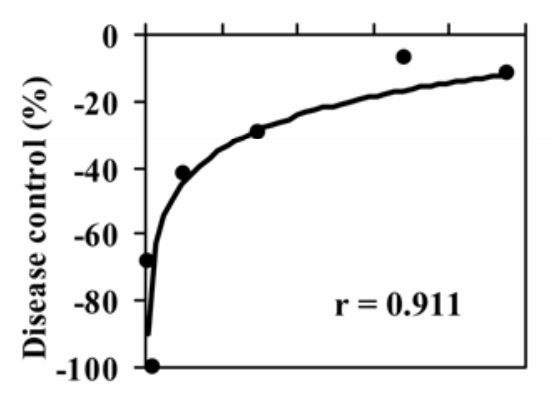

Fig. 4. Relationship between disease control in tubers from plants treated with foliar or infurrow applications of mefenoxam and effective concentration causing 50\% reduction of mycelial growth $\left(\mathrm{EC}_{50}\right)$ value of six Phytophthora erythroseptica isolates with varying degrees of resistance to mefenoxam. Exponential regression analysis is based upon mean of foliar and in-furrow mefenoxam treatments. fenoxam-insensitive isolates were significantly more aggressive on in-furrowtreated tubers compared with sensitive isolates (Table 1). The exception was high intermediate isolate 172-3, which did not differ in its aggressiveness index from either sensitive isolate when inoculated onto mefenoxam-treated tubers, regardless of the method of application. Aggressiveness indices were higher in tubers treated with foliar applications of mefenoxam for P. erythroseptica isolates with insensitivity to this fungicide compared with sensitive isolates; however, these differences were not always significant. High intermediate isolate 252-4 and resistant isolate PE-89 had the highest aggressiveness indices following mefenoxam treatment regardless of application method.

\section{DISCUSSION}

Pink rot has become an increasingly important disease of potato in recent years, especially in the production areas of North America. This situation is due, in part, to the development of resistance to mefenoxam within the $P$. erythroseptica population. Although fungicide resistance is a mitigating factor in the management of many plant diseases, resistance to mefenoxam is of particular importance where pink rot is concerned because it is the primary fungicide providing effective control of the pathogen. Mefenoxam may still provide adequate control of pink rot in many instances $(29,31,41,46)$; however, the appearance and spread of resistance within the pathogen population has created some unique challenges regarding management of the disease $(29,31,41-43,46)$.

Results reported here further demonstrate that field applications of mefenoxam will control isolates of $P$. erythroseptica sensitive to the fungicide. The current study also supports previous observations that in-furrow applications of mefenoxam are more effective than foliar applications in controlling pink rot $(41,46)$. In-furrow mefenoxam treatments provided 25 to $50 \%$ greater pink rot control than foliar applications in these studies, which is consistent with our previously published work (41).

Research dealing with pink rot and mefenoxam resistance often has focused upon in vitro screening of $P$. erythroseptica isolates for sensitivity to the fungicide $(1,14,21,31,42,43)$; however, studies involving other Peronosporales species demonstrated that resistance ascertained under in vitro conditions may not necessarily be expressed under in vivo conditions $(6,7,18,40)$ or subsequently translate into significant levels of disease in the field. The discovery of $P$. erythroseptica isolates with elevated insensitivity to the fungicide in vitro should serve as an alert that pink rot potentially could become a problem even under a mefenoxam treatment sched-

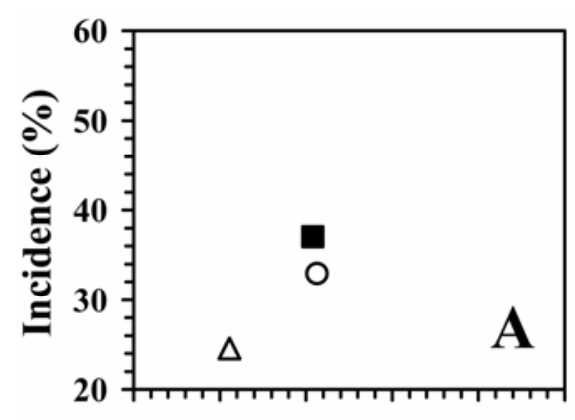

$\begin{array}{llllll}32.5 & 33.5 & 34.5 & 35.5 & 36.5 & 37.5\end{array}$

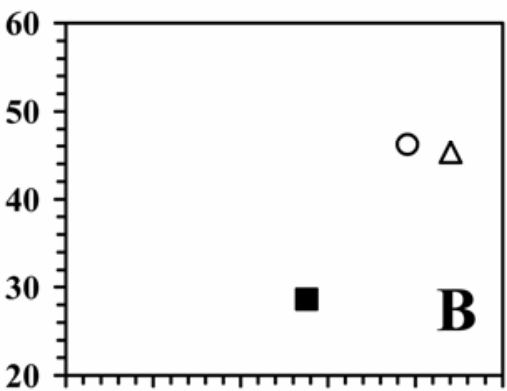

$\begin{array}{llllll}32.5 & 33.5 & 34.5 & 35.5 & 36.5 & 37.5\end{array}$
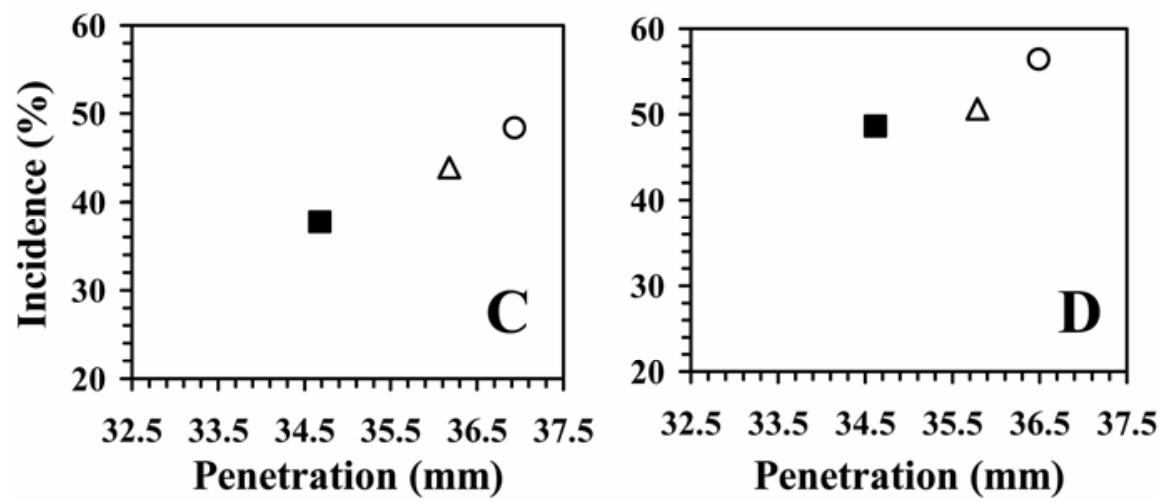

Fig. 5. Effect of mefenoxam resistance on disease incidence and depth of penetration in untreated tubers $(\boldsymbol{\square})$ and tubers from plants treated with either foliar $(\bigcirc)$ or in-furrow $(\Delta)$ applications of mefenoxam following inoculation with $\mathbf{A}$, sensitive, $\mathbf{B}$, low intermediate, $\mathbf{C}$, high intermediate, $\mathbf{D}$, and resistant isolates of Phytophthora erythroseptica. Symbols of mefenoxam treatments closer to the origin of the $\mathrm{X}-\mathrm{Y}$ axis denotes control of $P$. erythroseptica isolates with the fungicide whereas symbols distant from the $\mathrm{X}-\mathrm{Y}$ origin denotes increased disease severity relative to the untreated control. 
ule. However, other parameters may be involved for fungicide resistance to contribute to substantial preharvest or postharvest losses. These include such factors as aggressiveness both in the presence and absence of the fungicide, cultivar susceptibility, rates, timing, method of application, frequency of mefenoxam applications, and persistence of the fungicide in the environment.

Early work attempting to quantify the biological effect of metalaxyl within the potato-pathogen system used tissue slices (7) or tuber tissue disks (20). In these studies, fungicide was applied to excised tuber tissue that subsequently was inoculated with isolates of $P$. infestans. These experiments only examined highly sensitive and highly resistant isolates and did not include whole tubers from plants treated with the metalaxyl in the field. Results from such studies, although informative, do not account for the effects of the environment and the whole plant system upon hostpathogen interaction within the framework of fungicide pressure. Assessment of mefenoxam efficacy under natural conditions is an essential step in understanding the role of mefenoxam resistance in disease development and would provide more precise indication of isolate sensitivity. Research in this area, particularly regarding pink rot, has been limited. Peters and coworkers (31) used a sensitive $\left(\mathrm{EC}_{50}<\right.$ $\left.0.5 \mu \mathrm{g} \mathrm{ml}^{-1}\right)$, a moderately resistant $\left(\mathrm{EC}_{50}\right.$ $\left.=9.1 \mu \mathrm{g} \mathrm{ml}^{-1}\right)$, and a highly resistant $\left(\mathrm{EC}_{50}\right.$ $=518 \mu \mathrm{g} \mathrm{ml}^{-1}$ ) isolate of $P$. erythroseptica to inoculate tuber discs, wounded tubers, and whole tubers obtained from two cultivars treated with foliar applications of metalaxyl. Mefenoxam did not significantly reduce infection frequency following challenge inoculation with either resistant isolate. Similar results were obtained in a more expanded follow-up study (29) using wounded tubers and the same isolates. These studies demonstrated that the biologically significant level of resistance was 10 -fold lower than would be anticipated based upon in vitro testing alone. Our results agree with these findings but place this level of resistance an order of magnitude lower still, at an $\mathrm{EC}_{50}$ of approximately $1.0 \mu \mathrm{g} \mathrm{ml}^{-1}$.

Although this previous work $(29,31)$ demonstrated that a moderately resistant and a highly resistant isolate of P. erythroseptica were able to overcome the level of metalaxyl accumulated within tuber tissue following foliar applications of the fungicide, its effect upon infection frequency of these mefenoxam-resistant isolates varied greatly. In some cases, infection rates declined slightly following metalaxyl application whereas, in others, infection frequency apparently increased (29). This was most evident with the moderately resistant $\left(\mathrm{EC}_{50}=9.1 \mu \mathrm{g} \mathrm{ml}^{-1}\right)$ isolate following wounding, where disease incidence increased by up to $19 \%$ (29); however, the differences in infection frequency observed in those studies were not significant (29,31). Our results differ and probably are due to a combination of factors. Peters et al. $(29,31)$ used only two resistant isolates and we used six isolates of $P$. erythroseptica with varying levels of mefenoxam insensitivity. Additionally, in their studies, tubers were wounded prior to inoculation $(29,31)$; whereas, in our studies, we used nonwounded tubers for inoculations. The method of inoculation between previous work $(29,31)$ and studies reported here could largely explain the differences in the results obtained. $P$. erythroseptica infections occur primarily in the field $(22,23)$ and infection occurs via direct penetration in the absence of wounds. Studies performed by our research group involving the leak pathogen Pythium ultimum have demonstrated clearly that the wounding of tubers prior to inoculation breaches the barrier to the infection process provided by mefenoxam. Studies have shown that metalaxyl is not uniformly distributed throughout the tuber from outside (periderm) to the inside (cortex, medullary tissue) $(2,8)$ and that the level of metalaxyl in potato periderm can be significantly higher than elsewhere in the tuber (8). Infection rates may be altered if this protective barrier is breached (41) and this could introduce additional variability into the challenge inoculation experiments performed by Peters et al. $(29,31)$.

In work described here, mefenoxamresistant isolates of Phytophthora erythroseptica, regardless of the level of resistance determined by in vitro testing, consistently caused significantly more pink rot infections in tubers from plants treated with the fungicide. This appears to corroborate a belief based upon grower experience and our general field observations made under production conditions that pink rot often is more severe in fields with resistance in the $P$. erythroseptica population when mefenoxam is applied. If this is indeed the case, applications of mefenoxam could confound pink rot control and actually make the situation worse, particularly if a large portion of the population is insensitive to the fungicide. The significance of these results cannot be overlooked, because they have notable implications for potato producers who have mefenoxam-resistant populations of $P$. erythroseptica in their fields. Therefore, it may be prudent for potato growers to refrain from using mefenoxam-based fungicides under these conditions in an effort to avoid exacerbating a potential pink rot disease problem.

Fitness is a measure of an organism's ability to contribute to the gene pool of subsequent generations (15). It is determined by a genotype's ability to reproduce, grow, and survive through repeated life cycles. Previous work with $P$. infestans utilized four components (infection frequency, extent of tissue colonization, lesion area, and postinfection sporulation capacity) to develop a composite index as an estimate of the isolate fitness $(19,44)$. The current study involving $P$. erythroseptica, centered on two characteristics related to the process of pathogenesis to compare isolates, namely their ability to infect and colonize host tissue. These traits define an isolate's aggressiveness. Therefore, aggressiveness or, in our case, aggressiveness index, can be taken as one component contributing to an isolate's overall fitness. Other components include such factors as sporulation capacity (oospores, sporangia, and zoospores) and survival of these structures in soil over summer and winter environmental extremes. Fungicides also potentially may influence aggressiveness and the level of an isolate's fungicide sensitivity will directly impact the magnitude of this effect.

Previous work involving isolates of a number of other oomycete species found that resistance to metalaxyl did not negatively affect fitness. In those studies, resistant isolates had an equal or higher degree of competitive fitness in the absence of selection pressure than did sensitive isolates $(9,16,18,19,37)$. Similar results were obtained with the P. erythroseptica isolates in the current study. Under the criteria used here, we did not detect a reduction in aggressiveness in the resistant isolates. Based upon their level of aggressiveness, in the absence of mefenoxam, mefenoxamresistant isolates 217-1, PE-89, and 252-4 actually would be more competitive than the sensitive isolates in the field. These same mefenoxam-resistant isolates also are the most aggressive when placed under mefenoxam pressure. Although isolates 188-4 and 285-3 with low intermediate resistance to mefenoxam appeared to be less aggressive in the absence of selection pressure compared with the sensitive isolates, the enhanced infection rates they attained following mefenoxam applications provided a selective advantage as the population transitioned toward higher levels of mefenoxam resistance. Again, these data support the concept that the development of pink rot actually may be enhanced more in the presence of mefenoxam than without it.

A recent study using random amplified polymorphic DNA analysis failed to detect significant genetic variation in single zoospore cultures produced from $P$. erythroseptica isolates obtained from a variety of sites in North America (27). These observations suggest that the native population is relatively stable and that any novel genotypic variation would be due to mutation or migration of new strains on infected seed stocks or introduced via outcrossing in this homothallic fungus. Similarly, recent work dealing with the inheritance of mefenoxam resistance found 
the population to be relatively homogeneous for that trait (1). However, some variability was observed in two successive selfed generations (S1 and S2) of single oospore isolates, particularly in selfed isolates arising from parents with intermediate resistance to the fungicide. Substantial quantitative shifts toward increased insensitivity were detected in these isolates despite the absence of any mefenoxam selection pressure. Similar shifts were observed in the S2 progeny isolates. These results indicate that $P$. erythroseptica populations may be highly adaptive, particularly those containing phenotypes having intermediate resistance to mefenoxam. Such individuals would have a distinct advantage under mefenoxam selection pressure and the population could rapidly shift to proportionally more highly resistant phenotypes. Results obtained by our research group during a study of soil population dynamics of $P$. erythroseptica support this view (43). In that study, one sampling location with a mixed $P$. erythroseptica population shifted from 95\% sensitive and 5\% intermediate to $95 \%$ highly resistant phenotypes in just 2 years. The selective advantage possessed by the low intermediates such as 188-4 and 285-3 may be the driving force behind such a dramatic change in population composition. The inverse exponential relationship observed between mefenoxam sensitivity $\left(\mathrm{EC}_{50}\right)$ and disease control was unexpected but is indicative of the competitive advantage they possess. These isolates were less aggressive than the sensitive isolates 266-2 and 364-5 in the absence of mefenoxam but, based upon absolute numerical aggressiveness index values, appear to be more aggressive than the untreated sensitive isolates when inoculated to tubers from mefenoxam-treated plants.

The appearance of $P$. erythroseptica genotypes resistant to mefenoxam $\left(\mathrm{EC}_{50}>\right.$ $100 \mu \mathrm{g} \mathrm{ml}^{-1}$ ) has been a concern since the fungicide was approved for use on the potato crop. In light of the data presented here, populations containing isolates with low intermediate sensitivity to mefenoxam may be cause for even greater alarm. In the past, the biological significance of such isolates generally has been overlooked or not completely understood. Our results suggest that mefenoxam treatment may enhance the infection rates of such isolates and this has major implications for disease management. Generally, a common management tactic in areas where fungicide resistance has appeared is to suspend use of the product or increase the length of time between recommended applications, both within the current year and between growing seasons. This is done in anticipation of a decline in the resistant population and with the prospect that the fungicide ultimately can be reintroduced in the future as the sensitive proportion of the population increases. This strategy assumes that the resistant proportion of the population is less fit and that sensitive isolates eventually will fill that niche. Our results suggest that this would not be a practical approach for managing pink rot when mefenoxam resistance appears in local populations of $P$. erythroseptica.

Because of the selective advantage possessed by mefenoxam-resistant isolates, it may be necessary to reassess pink rot control strategy, including the use of longer rotations, resistant cultivars, and alternative fungicides. In order for mefenoxam to continue to be a viable control measure, the frequency of resistant isolates must be reduced in the population. Our results imply that competition between sensitive and insensitive genotypes may not accomplish this. New fungicides may provide one means of attaining this goal. Phosphorous acid (phosphonate or phosphite) has been used successfully to control a variety of diseases caused by species of Phytophthora $(3,5,13,26,47)$ and recent work suggests that it might provide an effective alternative to mefenoxam as a means of controlling pink rot under certain conditions (17). In addition, results of other recent work (30) suggest that crop rotation may influence the level of resistance to $P$. erythroseptica expressed by potato tubers. In order to design and develop alternative strategies to enhance the effectiveness and longevity of mefenoxam, an integrated approach may be necessary; therefore, it is essential that these issues be addressed.

Mefenoxam did not control $P$. erythroseptica isolates insensitive to the fungicide, even isolates with $\mathrm{EC}_{50}$ values as low as $1.1 \mu \mathrm{g} \mathrm{ml}^{-1}$. In the past, such isolates would be classified as having low intermediate resistance to the fungicide. They would be situated at the break point between insensitivity and sensitivity based upon rankings developed from $\mathrm{EC}_{50}$ data derived from in vitro testing. Because these isolates are not controlled with field applications of mefenoxam, it may be necessary to redefine "resistance" as "biologically significant resistance." In order to provide a more complete understanding of how it affects pink rot control, future research should consider this issue as well. In addition, fitness components not directly related to pathogenicity, also should be examined within this context.

\section{ACKNOWLEDGMENTS}

We thank D. Peterson, D. Serfling, D. Nilles, and C. Auwarter for technical assistance in conducting these experiments; and C. Doetkott, Statistician, Information Technology Services, North Dakota State University, for advice and assistance with data analysis.

\section{LITERATURE CITED}

1. Abu-El Samen, F. M., Oberoi, K., Taylor, R. J., Secor, G. A., and Gudmestad, N. C. 2005. Inheritance of mefenoxam resistance in selfed populations of the homothallic oomycete Phytophthora erythroseptica (Pethybr.), cause of pink rot of potato. Am. J. Potato Res. 82:105115.
2. Barak, E., Edgington, L. V., and Ripley, B. D 1984. Bioactivity of the fungicide metalaxyl in potato tubers against some species of Phytophthora, Fusarium, and Alternaria, related to polyphenoloxidase activity. Can. J. Plant Pathol. 6:304-308.

3. Bielenin, A., and Jones, A. L. 1988. Efficacy of sprays of fosetyl-Al and drenches of metalaxyl for the control of Phytophthora root rot and crown rot of cherry. Plant Dis. 72:477-480

4. Blodgett, E. C. 1945. Water rot of potatoes. Plant Dis. Rep. 29:124-126.

5. Browne, G. T., and Viveros, M. A. 2005. Effects of phosphonate and mefenoxam treatments on development of perennial cankers caused by two Phytophthora spp. on almond. Plant Dis. 89:241-249.

6. Bruck, R. I., Fry, W. E., and Apple, A. E. 1980. Effect of metalaxyl, an acylalanine fungicide, on development stages of Phytophthora infestans. Phytopathology 70:597-601.

7. Bruin, G. C. A., and Edgington, L. V. 1981. Adaptive resistance in Peronosporales to metalaxyl. Can. J. Plant Pathol. 3:201-206

8. Bruin, G. C. A., Edgington, L. V., and Ripley, B. D. 1982. Bioactivity of the fungicide metalaxyl in potato tubers after foliar sprays. Can. J. Plant Pathol. 4:353-356.

9. Cohen, Y., Reuveni, M., and Samoucha, Y. 1983. Competition between metalaxylresistant and -sensitive strains of Pseudoperonospora cubensis on cucumber plants. Phytopathology 73:1516-1520.

10. Cunliffe, C., Lonsdale, D., and Epton H. A. S. 1977. Transmission of Phytophthora erythroseptica on stored potatoes. Trans. Br. Mycol. Soc. 69:27-30.

11. Davidse, L. C., Looyen, D., Turkensteen, L. J., and Van der Wal, D. 1981. Occurrence of metalaxyl-resistant strains of Phytophthora infestans in Dutch potato fields. Neth. J. Plant Pathol. 87:65-68.

12. Dowley, L. J., and O'Sullivan, E. 1981. Metalaxyl-tolerant strains of Phytophthora in festans (Mont.) De Bary in Ireland. Potato Res. 24:417-421.

13. Forster, H. Adaskaveg, J. E., Kim, D. H., and Stanghellini, M. E. 1998. Effect of phosphite on tomato and pepper plants and on susceptibility of pepper to Phytophthora root rot and crown rot in hydroponic culture. Plant Dis. 82:1165-1170.

14. Goodwin, S. B., and McGrath, M. T. 1995. Insensitivity to metalaxyl among isolates of Phytophthora erythroseptica causing pink rot of potato in New York. Plant Dis. 79:967.

15. Hedrick, P. W. 1983. Genetics of Populations. Science Books International, Boston.

16. Holmes, S. J. I., and Chanon, A. G. 1984 Studies on metalaxyl-resistant Phytophthora infestans in potato crops in southwest Scotland. Plant Pathol. 33:347-354.

17. Johnson, D. A., Inglis, D. A., and Miller, J. S. 2004. Control of potato tuber rots caused by oomycetes with foliar applications of phosphorous acid. Plant Dis. 88:1153-1159.

18. Joseph, M. C., and Coffey, M.D. 1984. Development of laboratory resistance to metalaxyl in Phytophthora citricola. Phytopathology 74:1411-1414.

19. Kadish, D., and Cohen, Y. 1988. Fitness of Phytophthora infestans isolates from metalaxyl-sensitive and -resistant populations. Phytopathology 78:912-915.

20. Kadish, D., and Cohen, Y. 1988. Estimate of metalaxyl resistance in Phytophthora infestans. Phytopathology 78:915-919.

21. Lambert, D. H., and Salas, B. 1994. Metalaxyl insensitivity of Phytophthora erythroseptica isolates causing pink rot of potato in Maine. Plant Dis. 78:1010.

22. Lambert, D. H., and Salas, B. 2001. Pink rot. Pages 33-34. in: Compendium of Potato Diseases, 2nd ed. W. R. Stevenson, R. Loria, G. D. 
Franc, and D. P. Weingartner, eds. American Phytopathological Society, St. Paul, MN.

23. Lonsdale, D., Cunliffe, C., and Epton, H. A. S. 1980. Possible routes of entry of Phytophthora erythroseptica Pethyb. and its growth within potato plants. Phytopathol. Z. 97:109-117.

24. Millikin, G. A., and Johnson, D. E. 1992. Oneway treatment structure in a completely randomized design with heterogeneous errors. Pages 16-28 in: Analysis of Messy Data. Volume 1: Designed Experiments. Chapman and Hall, London.

25. Osusky, M., Osuska, L., Hancock, R. E., Kay, W. W., and Misra, S. 2004. Transgenic potatoes expressing a novel cationic peptide are resistant to late blight and pink rot. Transgenic Res. 13:181-190.

26. Ouimette, D. G., and Coffey, M. D. 1989. Comparative antifungal activity of four phosphonate compounds against isolates of nine Phytophthora species. Phytopathology 79:761767.

27. Peters, R. D., Clark, R. J., Coffin, A. D., Sturz, A. V., Lambert, D. H., and Miller, J. S. 2005. Limited genetic diversity in North American isolates of Phytophthora erythroseptica pathogenic to potato based upon RAPD analysis. Plant Dis. 89:380-384.

28. Peters, R. D., and Sturz, A. V. 2001. A rapid technique for the evaluation of potato germ plasm for susceptibility to pink rot. Plant Dis. 85:833-837.

29. Peters, R. D., Sturz, A. V., and Arsenault, W. J. 2003. Use of mefenoxam to control pink rot (Phytophthora erythroseptica) of potato in Prince Edward Island. Can. J. Plant Pathol. 25:33-40.

30. Peters, R. D., Sturz, A. V., Carter, M. R., and Sanderson, J. B. 2005. Crop rotation can confer resistance to potatoes from Phytophthora erythroseptica attack. Can. J. Plant Sci. 85:523-528.

31. Peters, R. D., Sturz, A. V., Matheson, B. G., Arsenault, W. J., and Malone, A. 2001. Metalaxyl sensitivity of isolates of Phytophthora erythroseptica in Prince Edward Island. Plant Pathol. 50:302-309.

32. Platt, B. 1994. Foliar application of fungicides affects occurrence of potato tuber rots caused by four foliar pathogens. Can. J. Plant Pathol. 16:341-346.

33. Powelson, M. L., Johnson, K. B., and Rowe, R. C. 1993. Management of diseases caused by soilborne pathogens. Pages 149-158 in: Potato Health Management. R. C. Rowe, ed. American Phytopathological Society, St. Paul, MN.

34. Reuveni, M., Eyal, M., and Cohen, Y. 1980. Development of resistance to metalaxyl in Pseudoperonospora cubensis. Plant Dis. 64:1108-1109.

35. Salas, B., Secor, G. A., Taylor, R. J., and Gudmestad, N. C. 2003. Assessment of resistance of tubers of potato cultivars to Phytophthora erythroseptica and Pythium ultimum. Plant Dis. 87:91-97.

36. Salas, B., Stack, R. W., Secor, G. A., and Gudmestad, N. C. 2000. The effect of wounding, temperature and inoculum density on the development of pink rot of potatoes caused by Phytophthora erythroseptica. Plant Dis. 84:1327-1333.

37. Sanders, P. I. 1984. Failure of metalaxyl to control Pythium blight on turfgrass in Pennsylvania. Plant Dis. 68:776-777.

38. Secor, G. A., and Gudmestad, N. C. 1999. Managing fungal diseases of potato. Can. J. Plant Pathol. 21:213-221.

39. Stamps, D. J., Waterhouse, G. M., Newhook, F. J., and Hall, G. S. 1990. Revised tabular key to the species of Phytophthora. Mycol. Pap. No. 162. CAB International Mycological Institute, Wallingford, Oxon, UK.

40. Staub, T., Dahmen, H., Urech, P., and Schwinn, F. 1979. Failure to select for in vivo resistance in Phytophthora infestans to acylalanine fungicides. Plant Dis. Rep. 63:385-389.

41. Taylor, R. J., Salas, B., and Gudmestad, N. C. 2004. Differences in etiology affect mefenoxam efficacy and the control of pink rot and leak tuber diseases of potato. Plant Dis. 88:301-307.

42. Taylor, R. J., Salas, B., Secor, G. A., Rivera, V., and Gudmestad, N. C. 2002. Sensitivity of North American isolates of Phytophthora erythroseptica and Pythium ultimum to mefenoxam (metalaxyl). Plant Dis. 86:797-802.

43. Taylor, R. J., Salas, B., Secor, G. A., Rivera, V. V., Oberoi, K., and Gudmestad, N. C. 2002 Mefenoxam resistance in the North American population of Phytophthora erythroseptica: Spatial distribution and frequency of resistance in soil and recombinant populations. Proc. Brighton Crop Prot. Conf. Pests Dis. 2:847 852 .

44. Tooley, P. W., Sweigard, J. A., and Fry, W. E. 1986. Fitness and virulence of Phytophthora infestans isolates from sexual and asexual populations. Phytopathology 76:1209-1212.

45. Vujicic, R., and Colhoun, J. 1966. Asexual reproduction in Phytophthora erythroseptica. Trans. Br. Mycol. Soc. 49:245-254.

46. Wicks, T. J., Davoren, C. W., and Hall, B. H. 2000. Fungicidal control of Phytophthora erythroseptica: The cause of pink rot on potato. Am. J. Potato Res. 77:233-240.

47. Wicks, T. J., and Hall, B. H. 1990. Control of Phytophthora canker with phosphonate in artificially inoculated almond and cherry trees. Aust. J. Exp. Agric. 30:413-420. 